\title{
Kemampuan Siswa Kelas V SD Negeri 6 OKU dalam Meringkas Wacana dengan Menggunakan Model Cooperative Integrated Reading and Composition (CIRC)
}

\author{
Awalludin $^{* 1}$, Rita Nilawijaya ${ }^{2}$ \\ Universitas Baturaja ${ }^{1,2}$ \\ Corresponding email: awalludinawri@gmail.com*
}

\begin{abstract}
The purpose of this study was to explain the ability of grade $V$ students of SD Negeri 6 OKU in summarizing discourse using the Cooperative Integrated Reading and Composition (CIRC) learning model. The method used in this research is descriptive method. The techniques used are observation and test techniques. The results showed that the fifth grade students of SD Negeri 6 OKU were able to summarize discourse using the Cooperative Integrated Reading and Composition (CIRC) learning model. This is evidenced by the average value of the students' ability in summarizing discourse using the Cooperative Integrated Reading and Composition (CIRC) learning model which is $63.83 \%$ which is in accordance with the assessment indicators which are classified as sufficient. In detail, the results of this study are: suitability of the summary content is $56 \%$ (sufficient), accuracy of themes is $60.66 \%$ (sufficient), suitability of word counts is $90.66 \%$ (very good), and mechanics is $48 \%$ (poor). In addition, the results of observations in this study indicate that the teacher delivers material summarizing discourse that can be understood by students through the application of the CIRC learning model which is well done and easy to understand.
\end{abstract}

Keywords: ability, summarize, discourse, CIRC learning model

\begin{abstract}
Abstrak
Tujuan penelitian ini adalah untuk menjelaskan kemampuan siswa kelas $\mathrm{V}$ SD Negeri 6 OKU dalam meringkas wacana dengan menggunakan model pembelajaran Cooperative Integrated Reading and Composition (CIRC). Metode yang digunakan dalam penelitian ini adalah metode deskriptif. Teknik yang digunakan adalah teknik observasi dan tes. Hasil penelitian menunjukkan bahwa siswa kelas V SD Negeri 6 OKU sudah mampu meringkas wacana dengan menggunakan model pembelajaran Cooperative Integrated Reading and Composition (CIRC). Hal ini dibuktikan dengan nilai rata-rata kemampuan siswa dalam meringkas wacana dengan menggunakan model pembelajaran Cooperative Integrated Reading and Composition (CIRC) adalah 63,83\% yang sesuai dengan indikator penilaian tergolong cukup. Secara rinci, hasil penelitian tersebut, yaitu: kesesuaian isi ringkasan 56\% (cukup), ketepatan tema 60,66\% (cukup), kesesuaian jumlah kata 90,66\% (baik sekali), dan mekanik $48 \%$ (kurang). Selain itu, hasil observasi dalam penelitian ini menunjukkan bahwa guru menyampaikan materi meringkas wacana dapat dipahami oleh siswa
\end{abstract}


melalui penerapan model pembelajaran CIRC yang dilakukan secara baik dan mudah dipahami.

Kata kunci: kemampuan, meringkas, wacana, model pembelajaran CIRC

\section{PENDAHULUAN}

Bahasa memiliki peranan yang sangat penting dalam kehidupan sehari-hari, karena bahasa merupakan alat untuk menyampaikan pikiran dan perasaan kepada orang lain. Sehubungan dengan hal itu, Keraf (2009:1) menyatakan bahwa bahasa adalah alat komunikasi antaranggota masyarakat, berupa simbol bunyi yang dihasilkan oleh alat ucap manusia (Noermanzah, 2019:307). Dengan adanya bahasa sebagai alat komunikasi, semua yang ada di sekitar manusia, seperti peristiwaperistiwa, binatang, tumbuhan, hasil ciptaan manusia, dan sebagainya, mendapat tanggapan dalam pikiran manusia, disusun dan diungkapkan kembali kepada orangorang lain sebagai bahan komunikasi.

Dalam bahasa kita mengenal ada empat keterampilan berbahasa pokok yaitu: menyimak, berbicara, membaca, dan menulis. Masing-masing keterampilan tersebut tersusun secara sistematis dan saling berhubungan antara satu dengan yang lain. Dalam memperoleh keterampilan berbahasa, biasanya melalui suatu hubungan urutan yang teratur; mula-mula, pada masa kecil, belajar menyimak/mendengarkan bahasa, kemudian berbicara, sesudah itu belajar membaca dan menulis (Tarigan, 2008:1).

Keterampilan berbahasa mempunyai hubungan yang erat dalam mendasari bahasa. Keterampilan tersebut hanya dapat diperoleh dan dikuasai dengan praktik dan banyak latihan. Membaca merupakan salah satu keterampilan berbahasa. Menulis tidak lepas dari membaca. Menulis merupakan suatu keterampilan berbahasa yang dipergunakan untuk berkomunikasi secara tidak langsung, tidak secara tatap muka dengan orang lain (Tarigan, 2008:4).

Menulis merupakan suatu kegiatan yang produktif dan ekspresif. Menulis ini tidak akan datang secara otomatis, melainkan melalui latihan dan praktik yang banyak dan teratur. Kemampuan menulis seseorang ditentukan oleh kemampuan membaca. Keterampilan menulis memerlukan kesungguhan untuk mengolah, menata, dan mempertimbangkan secara kritis gagasan yang akan dituangkan dalam bentuk tulisan (Awalludin, 2018:160; Noermanzah dkk., 2018:171-172; Awalludin dkk., 2020:32). Selanjutnya, menulis merupakan kegiatan yang menghasilkan suatu wacana. Wacana menjadi salah satu bidang linguistik yang relatif baru dan masih kurang mendapat perhatian para ahli bahasa pada umumnya, tetapi ditinjau dari kelengkapan unsurnya, wacana merupakan unit bahasa yang paling lengkap unsurnya (Darma, 2009:2-3).

Kelengkapan unsur-unsur wacana dapat diringkas atau dibuat ringkasan. Ringkasan adalah suatu cara yang efektif untuk menyajikan suatu karangan yang panjang dalam bentuk yang singkat (Keraf, 2009:299). Ringkasan merupakan penyajian singkat dari suatu karangan asli, tetapi dengan tetap mempertahankan urutan isi dan sudut pandang pengarang (Indrayatti, 2020;57-58). Terdapat beberapa cara meringkas sebuah wacana yaitu: membaca naskah asli, mencatat gagasan utama, membuat reproduksi, dan terdapat ketentuan tambahan (Magdalena, 2017:194-196).

Materi tentang meringkas atau membuat ringkasan sudah dipelajari pada siswa kelas V SD Negeri 6 OKU. Akan tetapi, kemampuan menulis ringkasan siswa 
masih kurang baik atau minim, karena kebanyakan siswa masih tetap menulis semua wacana yang ada tidak mengambil/mencatat gagasan utamanya saja. Hanya ada siswa yang dapat meringkas dengan baik, ada pula yang sudah meringkas, tetapi tidak urut dalam penyajiannya yang menjadikan wacana tersebut sulit untuk dipahami jalan ceritanya.

Berdasarkan paparan di atas, selayaknya seorang pendidik selalu melakukan perbaikan setelah dilakukan kegiatan evaluasi pemeblajaran terutama dalam pembelajaran keterampilan menulis yaitu membuat ringkasan. Hal ini sesuai dengan tugas pendidik dalam mengemban kompetensi pedagogik dan profesional yaitu melakukan kegiatan perencanaan pembelajaran, pelaksanaan pembelajaran, dan evaluasi pembelajaran secara berkelanjutan (Noermanzah, 2015:275). Perbaikan dalam pembelajaran tersebut yang dilakukan oleh guru adalah dengan menerapkan berbagai model pembelajaran inovatif dan memotivasi siswa agar siswa mampu membuat ringkasan. Salah satu model pembelajaran yang dilakukan guru adalah melalui model pembelajaran Cooperative Integrated Reading and Composition (CIRC). Magdalena (2017:194) dan Trianto (2011) menjelaskan dari hasil penelitiannnya bahwa model Cooperative Integrated Reading Composition (CIRC) mampu meningkatkan keterampilan siswa dalam menulis ringkasan dengan indikator penilaian dimulai dari isi gagasan. organisasi, tata bahasa, dan EYD. Kemudian, Frasandy \& Putri (2019:27) juga menjelaskan dari hasil penelitiannya bahwa model Cooperative Integrated Reading Composition (CIRC) yang digunakan sesuai karakteristik peserta didik sehingga meningkatkan kemampuan menulis ringkasan isi cerita kelas V MIN 1 Pesisir Selatan.

Oleh sebab itu, dari beberapa hasil penelitian relevan menunjukkan bahwa model Cooperative Integrated Reading Composition (CIRC) dengan keunggulannya memotivasi siswa dalam menulis diterapkan pada siswa kelas V SD Negeri 6 OKU dalam meningkatkan kemampuan meringkas wacana. Untuk itu, rumusan masalah penelitian yaitu "Bagaimanakah kemampuan siswa kelas V SD Negeri 6 OKU dalam meringkas wacana dengan menggunakan model pembelajaran Cooperative Integrated Reading and Composition (CIRC)? Tujuan penelitian ini untuk mendeskripsikan kemampuan siswa kelas V SD Negeri 6 OKU dalam meringkas wacana setelah diterapkannya model pembelajaran Cooperative Integrated Reading and Composition (CIRC). Hasil penelitian ini diharapkan bisa memberikan masukan kepada guru SD dan guru bahasa Indonesia bahwa model Cooperative Integrated Reading and Composition (CIRC) dapat dijadikan salah satu alternatif dalam meningkatkan kemampuan siswa dalam meringkas wacana.

\section{METODE}

Metode penelitian adalah cara yang digunakan oleh peneliti dalam mengumpulkan data penelitiannya (Arikunto, 2010:203). Adapun metode yang digunakan dalam penelitian ini adalah metode deskriptif. Metode deskriptif adalah metode yang benar-benar hanya memaparkan apa yang terdapat atau terjadi dalam sebuah kancah, lapangan, atau wilayah tertentu (Arikunto, 2010:3). Alasan peneliti menggunakan metode ini adalah untuk memaparkan dan mendeskripsikan kemampuan siswa kelas V SD Negeri $6 \mathrm{OKU}$ dalam meringkas wacana setelah diterapkannya model pembelajaran Cooperative Integrated Reading and Composition (CIRC) secara deskriptif. 
Untuk memperoleh dan mengumpulkan data penelitian ini, peneliti menggunakan teknik observasi dan tes. Adapun langkah-langkah dalam pengumpulan data dalam penelitian ini sebagai berikut.

1) Lembar soal dan petunjuk penulisan ringkasan dibagikan kepada siswa.

2) Alokasi waktu yang diberikan adalah $1 \times$ pertemuan $=2 \times 45$ menit.

3) Ringkasan yang telah selesai dikerjakan siswa dikumpulkan untuk diteliti.

4) Peneliti membaca dan memahami ringkasan siswa.

Teknik penganalisisan data tes dalam penelitian ini adalah penganalisisan data tes kemampuan siswa kelas V SD Negeri 6 OKU meringkas wacana dengan menggunakan model pembelajaran Cooperative Integrated Reading and Composition (CIRC). Adapun langkah-langkah yang peneliti lakukan sebagai berikut.

1) Mengumpulkan data dengan teknik tes berupa meringkas wacana.

2) Pemberian skor pada setiap lembar kerja siswa berdasarkan kriteria penilaian.

3) Menghitung nilai rata-rata kelas dalam menulis ringkasan dengan rumus yang telah dimodifikasi untuk kepentingan penelitian dengan rumus.

$\mathrm{NR}=\frac{\mathrm{JS}}{\mathrm{SM}} \times 100 \%$

4) Memasukkan skor rata-rata kelas dalam menulis ringkasan berdasarkan skala penilaian.

5) Mendeskripsikan dan menjelaskan hasil data yang diperoleh berdasarkan aspek yang dinilai, kemudian mencari rata-rata kelas dan memasukkan dalam skala penilaian.

6) Membuat simpulan.

\section{HASIL}

Data penelitian yang digunakan untuk mengetahui kemampuan siswa meringkas wacana dengan menggunakan model pembelajaran Cooperative Integrated Reading and Composition (CIRC) dalam pembelajaran yaitu tes dan observasi. Tes dilakukan pada hari Kamis tanggal 17 September 2020 pukul 08.0010.00 WIB di kelas V SD Negeri 6 OKU. Pengambilan sampelnya dilakukan secara keseluruhan jumlah siswa kelas $\mathrm{V}$ yang berjumlah 30 siswa. Setelah data tes kemampuan siswa diperoleh, lalu dianalisis berdasarkan nilai yang dicapai oleh siswa. Nilai ini diambil dari kemampuan siswa meringkas wacana dalam pembelajaran dengan model pembelajaran Cooperative Integrated Reading and Composition (CIRC), berdasarkan kriteria penilaian yang telah ditetapkan.

Berdasarkan analisis data yang dilakukan terhadap hasil meringkas wacana siswa kelas V SD Negeri 6 OKU dalam meringkas wacana dengan menggunakan Model Pembelajaran Cooperative Integrated Reading and Composition (CIRC) siswa kelas $\mathrm{V}$ SD Negeri 6 OKU yang mampu meringkas wacana dengan menggunakan Model Pembelajaran Cooperative Integrated Reading and Composition (CIRC) yang mendapat nilai 80 - 100 dengan predikat penilaian baik sekali berjumlah 0 orang atau 0, siswa yang mendapatkan nilai 66-79 dengan perdikat penilaian baik berjumlah 7 orang atau $23,33 \%$, siswa yang mendapat nilai $56-65$ dengan predikat penilaian cukup berjumlah 19 orang atau 63,33\%, siswa yang mendapat nilai 46-55 dengan predikat penilaian kurang berjumlah 4 orang atau $13,33 \%$, dan siswa yang mendapat nilai $00-45$ dengan predikat gagal berjumlah 0 orang atau $0 \%$.

Secara keseluruhan, kemampuan siswa kelas V SD Negeri 6 OKU dalam meringkas wacana setelah diterapkannya model pembelajaran Cooperative Integrated Reading and Composition (CIRC) termasuk katagori baik. Hal ini dapat 
dibuktikan dari nilai yang diperoleh siswa, siswa yang mendapatkan nilai 66-100 berjumlah 26 orang atau $86,66 \%$.

\section{PEMBAHASAN}

Berdasarkan data tes yang dilakukan peneliti dengan sampel 30 orang siswa yang mampu meringkas wacana setelah diterapkannya model pembelajaran Cooperative Integrated Reading and Composition (CIRC) sudah tergolong cukup baik. Keberhasilan ini dikarenakan model CIRC sebagai model pembalajaran yang komprehensif dalam proses membaca, tidak hanya siswa sekedar melakukan kegiatan membaca, tetapi melakukan diskusi kelompok. Kemudian, dalam model pembelajaran ini siswa diberikan kesempatan untuk mempresentasikan hasil diskusi mereka dan melakukan refleksi bersama agar mendapatkan hasil kegiatan meringkas yang terbaik (Magdalena, 2017:196). Teknik ini juga memperhatikan kebutuhan individu melalui kerja kelompok.

Kemampuan meringkas wacana yang cukup baik, dibuktikan dengan persentase yang diperoleh mencapai $63,83 \%$ yang sesuai dengan indikator penilaian tergolong cukup. Hal ini terbukti kesesuaian isi ringkasan 56\% dikatagorikan cukup, untuk kemampuan siswa pada ketepatan tema adalah 60,66\% dikatagorikan cukup, untuk kemampuan siswa pada kesesuaian jumlah kata adalah 90,66\% dikatagorikan baik sekali, dan untuk kemamapuan siswa pada mekanik adalah $48 \%$ dikatagorikan kurang.

Dari data yang diperoleh terdapat 26 orang siswa yang dikatakan baik dan cukup dalam meringkas wacana dengan menggunakan model pembelajaran Cooperative Integrated Reading and Composition (CIRC). Hal ini disebabkan siswa tersebut memahami dan menguasai dengan baik tentang meringkas wacana, terutama, kesesuaian isi ringkasan dan ketepatan tema dalam menulis ringkasan. Kemudian, ada 4 orang siswa yang mendapat nilai kurang, disebabkan siswa tersebut kurang menguasai cara meringkas khususnya dalam hal kesesuaian isi ringkasan dan mekanik. Hal ini penting dilakukan karena dalam meringkas dibutuhkan pemahaman bagi siswa terutama langkah-langkah dalam meringkas dengan menggunakan kemampuan mekanik dan EYD serta kemampuan dalam memaksimalkan keterampilan membaca (Haryati, 2013; Manullang \& Lubis, 2017).

Berdasarkan tes kemampuan siswa meringkas wacana dengan menggunakan model pembelajaran Cooperative Integrated Reading and Composition (CIRC) dengan sampel 30 orang siswa diperoleh rata-rata tingkat kemampuan 63,83\%. Apabila digunakan tolak ukur penilaian maka kemampuan siswa kelas V SD Negeri 6 OKU meringkas wacana dengan menggunakan model pembelajaran Cooperative Integrated Reading and Composition (CIRC) tergolong cukup karena berada pada interval $56-65 \%$. Bila dihubungkan dengan pembelajaran bahasa Indonesia, hasil penelitian ini menunjukkan bahwa meringkas wacana merupakan suatu pembelajaran yang tidak dapat diabaikan begitu saja di SD Negeri 6 OKU. Mengenai materi meringkas wacana ini menjadi fenomena yang perlu diperhatikan. Selain itu, fenomena ini tidak hanya dialami oleh guru, tetapi juga siswa, terkadang siswa menganggap remeh tentang materi meringkas wacana dan minat mereka dalam pembelajaran bahasa Indonesia juga kurang.

\section{KESIMPULAN DAN SARAN}

Kemampuan siswa kelas $\mathrm{V}$ SD Negeri 6 OKU dalam meringkas wacana dengan menggunakan model pembelajaran Cooperative Integrated Reading and Composition (CIRC) sudah cukup baik. Nilai aspek kesesuaian isi ringkasan berjumlah 84 atau 56\%, nilai aspek ketepatan tema berjumlah 91 atau 60,66\%, nilai aspek kesesuaian jumlah kata 
berjumlah 136 atau 90,66\%, dan nilai aspek mekanik berjumlah 72 atau 48\%, dengan nilai rata-rata siswa keseluruhan adalah $63,83 \%$.

Kemudian, siswa yang mendapatkan nilai $66-100$ berjumlah 26 orang siswa atau $86,66 \%$, siswa yang mendapatkan nilai $00-65$ berjumlah 4 orang siswa atau $13,33 \%$. Dengan demikian, siswa kelas $\mathrm{V}$ SD Negeri 6 OKU mampu meringkas wacana dengan menggunakan model pembelajaran Cooperative Integrated Reading and Composition (CIRC) dengan baik.

Sehubungan dengan hasil yang dicapai dalam penelitian ini, penulis menyampaikan beberapa saran kepada beberapa pihak, sebagai berikut.

1. Guru kelas V SD Negeri 6 OKU, khususnya Bidang Studi Bahasa Indonesia hendaknya dapat menerapkan model pembelajaran Cooperative Integrated Reading and Composition (CIRC) sebagai model variasi pengajaran di kelas.

2. Siswa, hendaknya dapat meningkatkan kemampuan meringkas wacana dan bekerja sama mencari solusi atas suatu permasalahan.

3. Peneliti, hendaknya dapat memperluas wawasan dan ilmu pengetahuan mengenai model pembelajaran Cooperative Integrated Reading and Composition (CIRC).

4. Peneliti lain, hendaknya dapat melakukan penelitian sejenis dan kajian subjek dan objek yang berbeda pada masa yang akan datang.

5. Pembaca, agar hasil penelitian ini dapat menambah pemahaman mengenai model pembelajaran Cooperative Integrated Reading and Composition (CIRC) dan memilih hal-hal yang patut dijadikan contoh dalam proses pembelajaran demi meningkatkan mutu pendidikan namun tidak terfokus pada hasil penelitian ini.

\section{DAFTAR PUSTAKA}

Arikunto, S. (2010). Prosedur Penelitian: Suatu Pendekatan Praktik. Jakarta: Rineka Cipta.

Awalludin, A., Sanjaya, M. R., \& Bataria, A. (2020). Hubungan Pemahaman tentang Surat-Menyurat terhadap Kemampuan Menulis Surat Dinas Siswa Kelas VII SMP Negeri 9 Oku. Diksa: Pendidikan Bahasa dan Sastra Indonesia, 6(1), 32. doi:10.33369/diksa.v6i1.11436

Awalludin, A. (2018). Efektivitas Model Decision Making dalam Pembelajaran Menulis Paragraf Persuasif Siswa Kelas X SMK Trisakti Baturaja. Jurnal Bindo Sastra, 2(1), 160. doi:10.32502/jbs.v2i1.923

Darma, Y.A. (2009). Analisis Wacana Kritis. Bandung: CV Yrama Widya.

Frasandy, R. N., \& Putri, S. (2019). Peningkatan Kemampuan Menulis Ringkasan Isi Cerita melalui Model Pembelajaran CIRC di MIN 1 Pesisir Selatan. INVENTA, 3(1), 27. doi:10.36456/inventa.3.1.a1805

Haryati, S. (2013). Meningkatkan Kemampuan Menulis Ringkasan Cerita dalam Pembelajaran Bahasa Indonesia melalui Model Snowball Throwing. Jurnal Teknologi Pendidikan, 2(1). doi:10.32832/tek.pend.v2i1.444 
Indrayatti, W. (2020). Kemampuan Menulis Ringkasan Teks Cerita Siswa Kelas VII Siswa Sekolah Menengah Pertama Kota Tanjungpinang Tahun 2019. Jurnal Kiprah, 8(1), 57-58. doi:10.31629/kiprah.v8i1.2072

Keraf, G. (2009). Komposisi. Semarang: Bina Putera.

Magdalena, R. (2017). Peningkatan Keterampilan Menulis Ringkasan Teks Bacaan melalui Model Pembelajaran Teknik CIRC (Cooperative Integrated Reading Composition). Deiksis, 9(02), 194-196. doi:10.30998/deiksis.v9i02.1605

Manullang, Y. N., \& Lubis, M. (2017). Hubungan Kemampuan Membaca Pemahaman dengan Kemampuan Menulis Ringkasan oleh Siswa Kelas VIII SMP Negeri 1 Medan Tahun Pembelajaran 2017/2018. Kode: Jurnal Bahasa, 6(4). doi:10.24114/kjb.v6i4.10836

Noermanzah, N. (2015). Peran Dosen Bahasa dan Sastra Indonesia dalam Mempertahankan Bahasa Indonesia sebagai Alat Pemersatu Negara Kesatuan Republik Indonesia pada Era Globalisasi. In Prosiding Seminar Nasional Bulan Bahasa 2015. Unit Penerbitan FKIP Universitas Bengkulu, p. 275. http://repository.unib.ac.id/11133/

Noermanzah, N. (2019). Bahasa sebagai Alat Komunikasi, Citra Pikiran, dan Kepribadian. Seminar Nasional Pendidikan Bahasa dan Sastra, Prosiding Seminar Nasional Bulan Bahasa (Semiba), 307, https://ejournal.unib.ac.id/index.php/semiba/article/view/11151/5537

Noermanzah, N., Abid, S., \& Aprika, E. (2018). Pengaruh Teknik Send a Problem terhadap Kemampuan Menulis Daftar Pustaka Siswa Kelas XI SMA Negeri 4 Lubuklinggau. Jurnal Kajian Bahasa, Sastra dan Pengajaran (KIBASP), 1(2), 171-172. doi:10.31539/kibasp.v1i2.273

Tarigan, H.G. (2008). Membaca: Sebagai Suatu Keterampilan Berbahasa. Bandung: Angkasa.

Trianto. (2011). Mendesain Model Pembelajaran Inovatif-Progresif. Jakarta: Kancana Prenada Media Group. 